\title{
Синтез раціональних структур бойових порядків спільних авіаційних груп
}

\author{
Леонід Артюшин ${ }^{1}$ А; Володимир Герасименко * 2 в; Володимир Коваль 3 с \\ А Державний науково-дослідний інститут авіації України, вул. Григорія Андрющенко 6В, м. Київ, 01135, Україна \\ в Національний університет оборони України імені Івана Черняховського, пр-кт Повітрофлотський 28, м. Київ, 03049, Україна \\ с Генеральний штаб Збройних Сил України, пр-кт Повітрофлотський 28, м. Київ, 03049, Україна
}

Received: June 5, 2021 | Revised: June 21, 2021 | Accepted: June 30, 2021

DOI: $10.33445 /$ sds.2021.11.3.20

\begin{abstract}
Анотація
Існуюча стратегія управління бойовим порядком, в основу якої покладено спосіб управління по ведучому або головному, природно, не могла стимулювати залучення апарату структурного аналізу для вирішення управлінських завдань. Майстерність пілотажу у складу групи зводиться до рівня підготовки льотчиків, можливості яких щодо контролю свого місця в бойовому порядку обмежені і укладаються в схему: ведучий ведений. Орієнтація на автоматизацію управління спільними бойовими порядками пілотованої та безпілотної авіації, при відсутності пілота на борту безпілотного літального апарату, виводить проблему за межі моделювання (імітації) дій льотчика при виконанні групового польоту і передбачає постановку завдань структурної та параметричної оптимізації строю пілотованих та безпілотних літальних апаратів в межах бойового порядку. Сутність проблеми полягає у істотному підвищенні ефективності існуючих принципів управління та реалізації принципово нових способів управління бойовими порядками, що спираються, у тому числі, і на все зростаючі можливості засобів міжлітакової навігації та контролю місця літака в бойовому порядку. Один із шляхів досягнення зазначених цілей вбачається в розробці методів пошуку стійких і добре керованих структур.
\end{abstract}

Ключові слова: бойовий порядок, спільна авіаційна група, автоматизація управління, складний граф, матриця структури, раціональна структура.

\section{Постановка проблеми}

Одна і та ж форма бойового порядку може бути реалізована за допомогою різної організації внутрішньо системних зв'язків [1]. Оцінка можливостей різних структур [2], незалежно від динамічних властивостей елементів бойового порядку, представляє досить істотний інтерес у загальній проблемі автоматизації управління групами літальних апаратів.

\section{Аналіз останніх досліджень та публікацій}

Множини перетворень внутрішнього закону руху системи або способу їі дії визначають певні початкові значення вхідних (вихідних) векторів системи з подальшим присвоєнням нових значень цим векторам. Процедура організації внутрішньо системних зв'язків наведена у [1]. Визначення процедур оцінки складності і максимальної довжини інформаційного циклу графів описано у [2]. Абстрагування від кількісного складу деякої множини елементів представляє логічним вимір складності такої множини числом їі елементів. Різноманітність цих елементів зручно оцінювати, спираючись на поняття

\footnotetext{
1 доктор технічних наук, професор, провідний науковий співробітник, e-mail: artleonid2017@gmail.com, ORCID: 0000-0002-7488-7244

2 * Corresponding author: кандидат військових наук, докторант, e-mail: gerasimenko_v_v@nuou.org.ua, ORCID: 0000-0003-2014-7408

3 кандидат військових наук, с.н.с., начальник воєнно-наукового управління, e-mail: gera410@ukr.net, ORCID: 0000-0002-6209-6779
} 
ентропії з статистичної теорії інформації, що наведено у [3]. Опис графічного та аналітичного вирішення досліджуваної оптимізаційної задачі 3 класу задач дискретного програмування наведено у [4-6]. Особливості тактичних та технічних аспектів організації управління бойовими порядками спільних авіаційних груп наведено у [7-9]. Порядок опису елементів та етапів польоту 3 використанням методу опорних точок наведено у [10].

\section{Постановка завдання}

Отже, метою статті $\epsilon$ розроблення оптимізаційних процедур, що сприятимуть синтезу стратегій управління спільними авіаційними групами та суттєво звузить область пошуку раціональних структур бойових порядків пілотованої та безпілотної авіації.

\section{Виклад основного матеріалу}

Розглянемо авіаційну структуру на прикладі такого розповсюдженого бойового порядку тактичного підрозділу (ланки) як клин (мал. 1).

Тут проглядаються три рівні ієрархічної структури, для пілотованої авіації: система ланка, підсистема - пара, елемент літальний апарат; для безпілотної авіації: система - ескадрилья, підсистема - ланка, елемент - літальний апарат. В даному бойовому порядку для безпілотної авіації неподільною підсистемою $€$ ланка. Ланки можуть виконувати різні завдання, отже, і характер зв'язків між ланками може змінитися. Тому, сформуємо матриці зв'язків для кожної 3 ланок безпілотних літальних апаратів - чотирьох підсистем $E_{1}, E_{2}, E_{3}, E_{4}$,

$S_{1}=\left[\begin{array}{cccc}0 & S_{12}^{(i)} & 0 & S_{14}^{(i)} \\ S_{21}^{(i)} & 0 & 0 & 0 \\ S_{31}^{(i)} & 0 & 0 & 0 \\ 0 & 0 & S_{43}^{(i)} & 0\end{array}\right], \quad i=1,2,3,4$

які відображають зв'язки елементів системи:

$$
X_{r}^{(s)}=S_{s r} Y^{(r)}, r, s=\overline{1, N} ; r \neq s .
$$

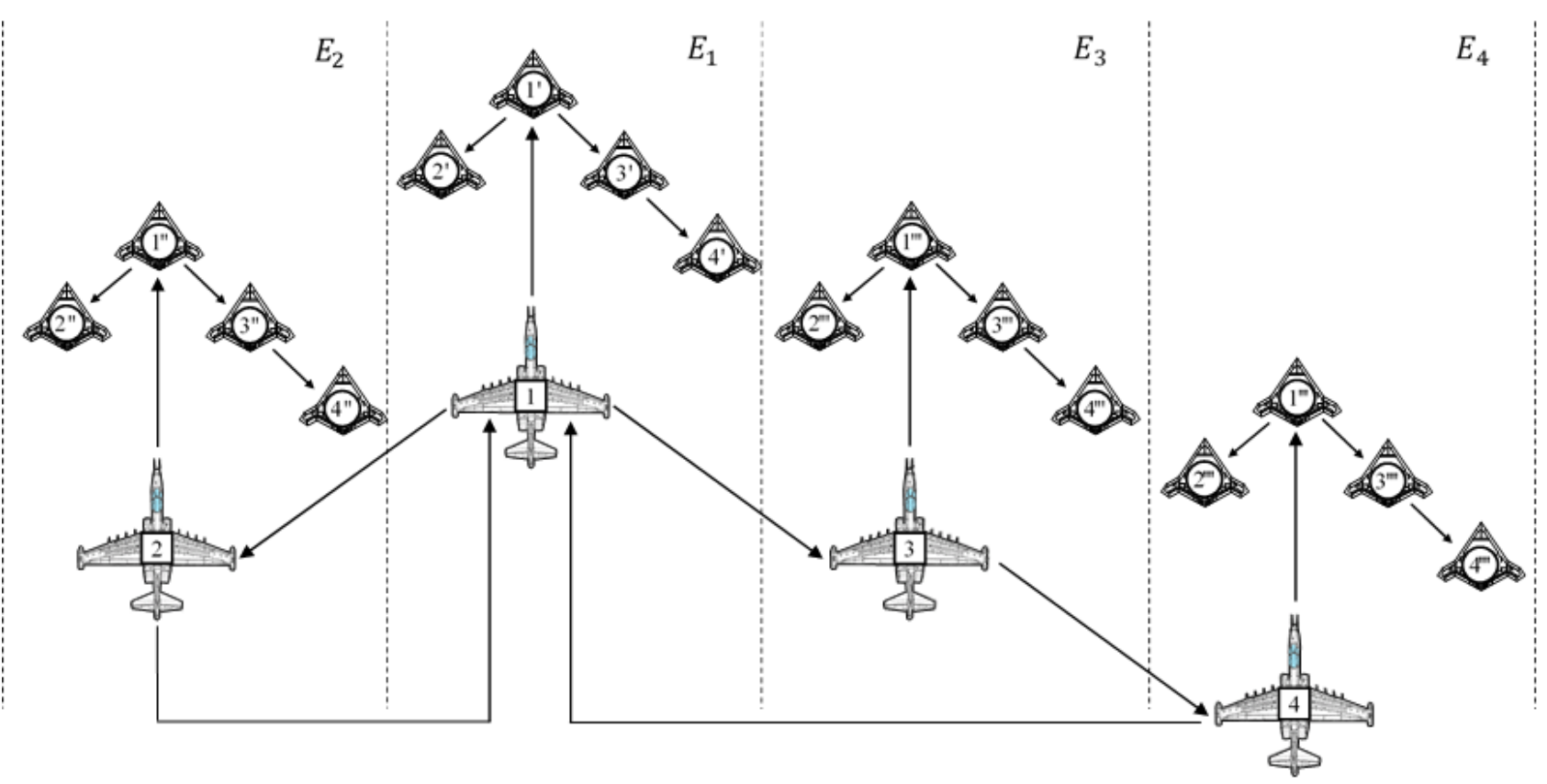

Малюнок 1 - Бойовий порядок тактичного підрозділу (ланки) пілотованої авіації $(1,2,3,4)$ клин; безпілотної авіації ('; "; '"'; '”'’) - клин ланок 
Індекс $r$ при $X_{r}^{(s)}$ означає, що цей вектор $\epsilon$ станом входів $e_{s}$ i $\in$ результатом зв' язку з $e_{r}$.

Кожен елемент системи володіє якимсь властивим йому внутрішнім законом руху. Якщо позначити $T_{r}$ - перетворення, що виражає спосіб дії елементу $e_{r}$, то отримаємо $N$ таких перетворень:

$$
Y_{r}^{(r)}=T_{r} X^{(r)}, \quad(r, s=\overline{1, N} ; r \neq s) .
$$

Підставляючи (3) в (2), перетворення можна представити у вигляді (де позначено $S_{s r} T_{r}=R_{s r}$ )

$$
X_{r}^{(s)}=R_{s r} X^{(r)}, \quad r, s=\overline{1, N} ; r \neq s .
$$

Якщо векторні рівності (2) піддати перетворенням (3), то отримаємо

$$
T_{s} X_{r}^{(s)}=T_{s} S_{s r} Y^{(r)},
$$

і, відповідно,

$$
Y_{r}^{(s)}=T_{s} S_{s r} Y^{(r)}, \quad(r, s=\overline{1, N} ; r \neq s) .
$$

Прийнявши

$$
T_{s} S_{s r}=P_{s r},
$$

ці перетворення можна записати у вигляді

$$
Y_{r}^{(s)}=P_{s r} Y^{(r)} \text {. }
$$

Множина перетворень (4) і (7) приписує певним початковим значенням вхідних (вихідних) векторів системи нові значення цих векторів. Ця множина відображає внутрішній закон руху системи, або спосіб їі дії [1].

Складний вектор, складові якого $\epsilon$ вхідними векторами окремих елементів, що належать системі, назвемо вектором станів входів системи і позначимо його $\bar{X}: \bar{X}=$ $\left(X^{(1)}, \ldots, X^{(N)}\right)$. Тоді для вектору станів виходів системи запишемо:

$$
\bar{Y}=\left(Y^{(1)}, Y^{(2)}, \ldots, X^{(N)}\right) .
$$

Множину перетворень (2) еквівалентно матричній рівності, ліві частини яких у вигляді складних векторів

$$
\begin{aligned}
& \bar{X}_{k}=\left(X_{k}^{(1)}, X_{k}^{(2)}, \ldots, X_{k}^{(N)}\right), \\
& \bar{Y}_{k}=\left(Y_{k}^{(1)}, Y_{k}^{(2)}, \ldots, Y_{k}^{(N)}\right),
\end{aligned}
$$

матричні нерівності (4) і (7) можна записати у вигляді

$$
\begin{aligned}
& \bar{X}_{k}=R \bar{X}, \\
& \bar{Y}_{k}=P \bar{Y} .
\end{aligned}
$$

де $R$ і $P$ - оператори перетворення; $\bar{X}$ i $\bar{Y}-$ початковий стан входів і виходів всіх елементів системи; $\bar{X}_{k}$ і $\bar{Y}_{k}-$ новий стан входів і виходів після перетворень.

Аналогічно можна записати в еквівалентній формі векторні рівності (2)

$$
\bar{X}_{k}=\bar{Y} S,
$$

де $S$ - матриця структури системи.

Перетворення (8) i (9), таким чином, знаходяться в тісному взаємозв'язку.

Через $T$ позначимо діагональну матрицю

$$
T=\left[\begin{array}{cccc}
T_{1} & 0 & \ldots & 0 \\
0 & T_{2} & \ldots & 0 \\
0 & 0 & \ldots & T_{N}
\end{array}\right],
$$

ненульові елементи якої утворюють оператори перетворень, що відповідають окремим елементам системи. Така матриця називається матрицею способів дій елементів системи. Оператори $R$ і $P$ представимо у вигляді добутків

$$
\begin{aligned}
& R=T S, \\
& P=S T,
\end{aligned}
$$

де $S$ - матриця структури системи.

Тоді спосіб дії системи можна записати у векторному вигляді:

$$
\begin{gathered}
\bar{X}_{k}=T S \bar{X}, \\
\bar{Y}_{k}=T S \bar{Y} .
\end{gathered}
$$

Такий сукупний опис способу дії елементів і структури системи повністю визначає систему як об'єкт дослідження.

Складемо математичний опис підсистем ланок БПЛА $\Sigma_{i}(i=1,2,3)$. Крім векторів станів входів і виходів підсистеми $\bar{X}^{\prime}$ і $\bar{Y}^{\prime}$ (вектори входів і виходів сукупності елементів підсистеми $\Sigma_{i}$ ) необхідно враховувати зв' язок підсистеми з зовнішнім середовищем через вектори її входу $\bar{X}_{c}^{\prime}$ і виходу $\bar{Y}_{c}^{\prime}$. Штрих над буквою означає, що позначення відносяться до підсистеми $\Sigma_{i}$. 
При цьому в системі всі можливі зв'язки однозначно враховуються, наступними матрицями: $S_{E C}$ - матрицею зв'язку вектор входу сукупності елементів з вектором входу підсистеми; $S_{C E}-$ матрицею зв'язку вектору виходу підсистеми 3 вектором виходу сукупності елементів; $S_{E E}-$ матрицею зв'язку входів елементів з виходами (структура підсистеми); $S_{c c}-$ матрицею зв'язку виходу системи зі входом.

Тоді перетворення "вхід - структура підсистеми - вихід” для досліджуваної підсистеми описується системою рівнянь, де $S$ - матриці зв'язків відповідних векторів,

$$
\left\{\begin{array}{l}
\bar{X}^{\prime}=S_{\bar{X}^{\prime} \bar{X}^{\prime}} \bar{X}^{\prime}+S_{\bar{X}^{\prime} \bar{Y}^{\prime}} \bar{Y}^{\prime}+S_{\bar{X}^{\prime} \bar{X}_{C}^{\prime}} \bar{X}_{C}^{\prime}+S_{\bar{X}^{\prime} \bar{Y}_{C}^{\prime}} \bar{Y}_{C}^{\prime} \\
\bar{Y}_{C}^{\prime}=S_{\bar{Y}_{C}^{\prime} \bar{X}^{\prime}} \bar{X}^{\prime}+S_{\bar{Y}_{C}^{\prime} \bar{Y}^{\prime}}+S_{\bar{Y}_{C}^{\prime}} \bar{X}_{C}^{\prime}+S_{\bar{Y}_{C}^{\prime} \bar{Y}_{C}^{\prime} \bar{Y}_{C}^{\prime}}=T^{\prime} \bar{X}^{\prime}
\end{array} .\right.
$$

Розв'яжемо систему рівнянь для тобто знайдемо рівняння, що зв'язує вхід i перетворення “вхід - структура підсистеми - вихід системи, яке прийме вигляд вихід" для досліджуваної підсистеми (15),

$$
\bar{Y}_{c}^{\prime}=\left[E-\left\{C S_{\bar{X}^{\prime} \bar{Y}_{c}^{\prime}}+S_{\bar{Y}_{c}^{\prime} \bar{Y}_{c}^{\prime}}\right\}\right]^{-1}\left(C S_{\bar{X}^{\prime} \bar{X}_{c}^{\prime}}+S_{\bar{Y}_{c}^{\prime} \bar{X}_{c}^{\prime}}\right) \bar{X}_{c}^{\prime}
$$

де

$$
C=\left(S_{\bar{Y}_{c}^{\prime} \bar{X}^{\prime}}\left(T^{\prime}\right)^{-1}+S_{\bar{Y}_{c}^{\prime} \bar{Y}^{\prime}}\right)\left[\left(E-S_{\bar{X}^{\prime} \bar{X}^{\prime}}\right)\left(T^{\prime}\right)^{-1}-S_{\bar{X}^{\prime} \bar{Y}^{\prime}}\right]^{-1} .
$$

Таким чином, для опису підсистеми необхідно:

1) скласти матрицю перетворень елементів підсистеми

$$
T^{\prime}=\left[\begin{array}{cccc}
T_{1}^{\prime} & 0 & 0 & 0 \\
0 & T_{2}^{\prime} & 0 & 0 \\
0 & 0 & T_{3}^{\prime} & 0 \\
0 & 0 & 0 & T_{1}^{\prime}
\end{array}\right]
$$

2) описати вектори:

$\bar{X}_{c}^{\prime}$ і $\bar{Y}_{c}^{\prime}$ - входи і виходи підсистеми $\Sigma_{1}$ відповідно;

$\bar{X}^{\prime}=\left(X^{(1)}, X^{(2)}, X^{(3)}, X^{(4)}\right)$ - входи сукупності елементів;

$\bar{Y}^{\prime}=\left(Y^{(1)}, Y^{(2)}, Y^{(3)}, Y^{(4)}\right)-$ виходи сукупності елементів;

3) записати рівняння входів сукупності елементів рівняння виходу підсистеми

$$
\begin{cases}X^{(1)}=\bar{X}_{c}^{\prime}+\bar{Y}_{c}^{\prime} & X^{(3)}=Y^{(1)} \\ X^{(2)}=Y^{(1)} & X^{(4)}=Y^{(3)}\end{cases}
$$

та рівняння виходу підсистеми $\bar{Y}_{c}^{\prime}=Y^{(4)}+Y^{(2)}$;

4) побудувати матриці зв' язків в підсистемі розмірності $4 \times 4$ (склад ланки налічує чотири літаки): $S_{\bar{X}^{\prime} \bar{X}^{\prime}}, S_{\bar{X}^{\prime} \bar{Y}^{\prime}}, S_{\bar{X}^{\prime} \bar{X}_{c}^{\prime}}, S_{\bar{X}^{\prime} \bar{Y}_{C}^{\prime}}, S_{\bar{Y}_{C}^{\prime} \bar{Y}^{\prime}, .}$

Для пари $\Sigma_{1}$ рівняння (16) має вигляд

$\bar{Y}_{c}^{\prime}=\left[\left[S_{\bar{Y}_{c}^{\prime} \bar{X}^{\prime}}\left(\left(T^{\prime}\right)^{-1}-S_{\bar{X}^{\prime} \bar{Y}_{c}^{\prime}}\right)\right]-S_{\bar{X}^{\prime} \bar{Y}_{c}^{\prime}}\right] \bar{S}_{\bar{X}^{\prime} \bar{X}_{c}^{\prime}} \times \bar{X}_{c}^{\prime}$,

що і $€$ описом підсистеми $\Sigma_{1}$.
Опис клину ланок здійснюється аналогічно тому, як це робилося для ланки. При цьому матриця структури всієї системи $\Sigma$ записується в такий спосіб:

$$
S=\left[\begin{array}{cccc}
S_{1} & 0 & S_{13} & S_{14} \\
S_{21} & S_{2} & 0 & S_{24} \\
0 & S_{32} & S_{3} & S_{34} \\
S_{41} & S_{42} & S_{43} & 0
\end{array}\right] .
$$

Матриця $S$ складена з шести підматриць, які, в свою чергу, складені з підматриць $S_{s r}$, що виражають зв' язки елементів в підсистемах $\Sigma_{i}$ $(i=1,2,3,4)$. Підматриці виражають: $S_{12}-$ зв'язок елементів підсистеми $\Sigma_{1} 3$ елементами підсистеми $\Sigma_{2} ; S_{23}$ - зв'язок елементів $\Sigma_{2}$ підсистеми 3 елементами підсистеми $\Sigma_{3} ; S_{31}$ - зв'язок елементів підсистеми $\Sigma_{3}$ з елементами підсистеми $\Sigma_{1}$, або, інакше, зворотний зв'язок елементів трьох підсистем; $S_{i}(i=1,2,3,4)$ - матриці структури систем $\Sigma_{i}$.

При аналізі формул (13) і (14) для систем вищих порядків за аналогією з підсистемою можна зробити висновок, що такі системи володіють новими властивостями, своїм способом дії (законом руху), що залежать не тільки від способів дії систем першого порядку, а й від структури взаємозв'язків елементів різних підсистем першого порядку, це прояв 
емерджентності в системі. Зв'язки ці виражаються в матрицях структур підсистем $S_{\text {. }}$.

Перетворення "вхід - клин ланок - вихід" буде описуватися системою рівнянь (14)

$$
\left\{\begin{array}{l}
\bar{X}=S_{\overline{X X}} \bar{X}+S_{X Y} \bar{Y}+S_{\overline{X X}_{c}} \bar{X}_{c}+S_{\overline{X Y}_{c}} \bar{Y}_{c} \\
\bar{Y}_{c}=S_{\bar{Y}_{c} \bar{X}} \bar{X}+S_{\bar{Y}_{c} \bar{Y}} \bar{Y}+S_{\bar{Y}_{c} \bar{X}_{c}} \bar{X}_{c}+S_{\bar{Y}_{c} \bar{Y}_{c} \bar{Y}_{c}} \\
\bar{Y}=T \bar{X}
\end{array}\right.
$$

де $\bar{X}_{c}$ і $\bar{Y}_{c}$ - вхід і вихід системи; $S_{\overline{X Y}}-$ матриця структури зв'язків системи (17).

Тоді, повторивши всі операції, що проводяться вище стосовно до ланки, для системи в цілому отримаємо оперативноструктурне перетворення всього бойового порядку - клин ланок. Вид цього перетворення відповідає виразу (16). Зміст його визначається конкретною структурою системи. Рівняння зв'язків системи виходять формально 3 використанням матричного алгоритму. При цьому ступінь деталізації структури бойового порядку визначається 3 міркувань тактики дії підрозділу при виконанні бойового завдання самостійно або в складі більш великих формувань. Зміна опису системи відповідно до зміни ії структури здійснюється переконструюванням матриць зв'язку. Причому, маючи на увазі реалізацію такого порядку в системі управління, ці матриці можуть бути або визначені заздалегідь і відповідати множині можливих режимів (різної конфігурації строю при виконанні різних завдань) системи, або змінюватися в процесі роботи в функції деяких заданих параметрів.

Від викладення узагальненої моделі бойового порядку, як системи, перейдемо до опису особливостей структур. Наочно і конструктивно його можна провести, спираючись на теорію графів. Якщо бойовий порядок уявити модельним графом, то процес рішення можна звести до опису графа, що відповідає певним вимогам і $\epsilon$ оптимальним за якимсь з його інваріантів.

В узагальненій постановці задачу сформулюємо наступним чином. Нехай $G$ побудований клас графів, що задовольняє вимогам і обмеженням, накладеним на систему. $\Phi(g), g \in G$ - деякий інваріант, що інтерпретує критерій оптимальності системи. Необхідно знайти підклас Ф оптимальних в $G$ графів. Чітко проглядається дві взаємопов'язані задачі теорії графів: побудова класу графів $G$, елементи якого задовольняють заданим вимогам; опис $\Phi$ оптимальних в $G$ графів.

Щодо вибору критеріїв оптимальності можна стверджувати, що найбільш прийнятними виявляться ті висновки, на основі яких мають вихід, який проглядається на практичну реалізацію. 3 огляду на специфіку задачі, до них слід віднести складність графа і максимальну довжину інформаційного циклу $L$.

B основу пошуку шуканої сукупності вершин і дуг покладемо:

кількість елементів системи, що визначає число вершин графу;

вимоги замкнутості, що з точки зору організації управління передбачає наявність в тій чи іншій формі зворотних зв'язків;

принцип організації зв'язків, при якому забезпечується наявність тільки одного прямого зв'язку між взаємодіючими елементами;

оцінку складності графу і максимальної довжини інформаційного циклу.

Перш ніж остаточно сформулювати завдання, зробимо ряд зауважень. Складну механічну систему будемо інтерпретувати орграфом $G=(X, U)$, де $X$ - множина вершин графа (відповідає множині елементів системи), а U-множина дуг графа (відповідає множині зв'язків між елементами). Через $D(G, X)$ позначимо множину досяжних вершин $x \in X$ графа $G=(X, U)$.

Визначення 1. Множина $U^{\prime} \subseteq U$ називається базою дуг графа $G=(X, U)$, якщо:

1. $\forall x \in X\left[D^{\prime}(X)=D(X)\right]$;

2. $\forall U^{\prime \prime} \subset U^{\prime} \exists x \in X\left[D^{\prime}(X) / D^{\prime \prime}(X)=\emptyset\right]$, де $D^{\prime}(X)=D\left(G^{\prime}, X\right), D^{\prime \prime}(X)=D\left(G^{\prime \prime}, X\right)$.

Суграф $G$ будемо називати базовим графом, якщо база дуг графа $G^{\prime}$. Через $Z(X, Y)$ позначимо множину всіх простих ланцюгів з вершин $X$ в $Y$. Всі можливі зв'язки для заданого числа елементів системи $(n)$ описуються повним графом Бержа без петель (мал. 2). 


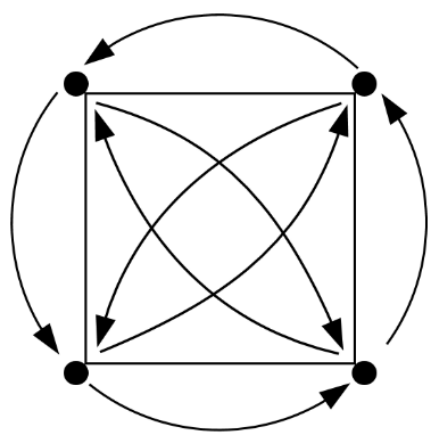

Малюнок 2 - Повний граф Бержа без петель для можливих зв' язків заданого числа елементів системи ( $n)$

Тепер в категоріях теорії графів задача синтезу оптимальної системи зв'язків формулюється так: знайти базовий суграф повного графа Бержа $G\left(X, U_{b}\right)$, для заданого $n=|X|$, такий що $\forall x, y \in X[|Z(x, y)|=$ $|Z(y, x)|=1]$ і для якого функціонал $F(G)=$ $\alpha W(G)+\beta L(G)$ має мінімальне значення. Тут $\alpha$ і $\beta$ - вагові коефіцієнти, які визначаються специфікою задачі.

Булев метод відшукання всіх базових графів повного графа Бержа, незважаючи на його теоретичну простоту і логічність, навряд чи виявиться раціональним стосовно до дослідження графів, що описують реальні авіаційні бойові порядки, кількісні характеристики яких можуть змінюватися в досить широкому діапазоні. Уникнути описаних труднощів і досягти бажаних результатів можна, спираючись на доведену теорему і метод синтезу суграфів 3 багатокутників, що використовує операції стягування і склеювання.

Теорема. Якщо $U^{\prime}-$ база дуг бізв'язного орграфа $G=(X, U)$, тоді

$$
|X| \leq\left|U^{\prime}\right| \leq 2|X|-2 .
$$

Причому, якщо $\left|U^{\prime}\right|=|X|$, то базовий суграф $G^{\prime}=\left(X, U^{\prime}\right)$ являється гамільтоновим контуром, а якщо $\left|U^{\prime}\right|=2|X|-2$, то базовий суграф - граф з двокутниками.

В результаті операції стягування ребра (дуги) вихідний граф $G$ перетворюється в інший, з числом вершин $h(G)-1$ і числом ребер $m(G)-1$. Суть стягування полягає в тому, що ребро $\overrightarrow{x y}$ видаляється, а інцидентні йому вершини $x$ та у замінюються однією, що позначається $x y$. Вершина $x y$ оголошується суміжною тільки з тими вершинами множини $X /(x, y)$, які в $G$ були суміжні хоча б з однією 3 вершин $x$ або $y$. Суміжність вершин множини $X /(x, y)$ залишається незмінною. Операція стягування ребра для випадку, коли вершини $x$ і $y$ не $є$ суміжними, називається операцією склеювання. Шляхом ії одноразового застосування число вершин зменшується на одиницю, а число ребер (дуг) може залишатися незмінним.

Визначення 2. Бізв'язний граф, для якого $S^{+}(x)=S^{-}(y)=/ \forall \mathrm{x} \in \mathrm{X}, \quad$ називається $n$ кутником $(n=|X|)$ або гамільтоновим контуром.

Визначення 3. Бізв'язний граф, що не містить простих орциклів довжини $L>2$, називається графом з двокутником. Теорема дозволяє з множини базових суграфів виділити суграф з мінімальною кількістю дуг (гамільтонів контур) і базовий суграф 3 максимальною кількістю ребер (граф 3 двокутником). Проілюструємо сказане на прикладі ланки $n=|X|=4$. Відповідно до (19), $4 \leq m\left(G^{\prime}\right) \leq G$.

Причому, виходячи з висновків теореми, при $m(G)=4$, базовий суграф $G^{\prime}$ являє собою гамільтонів контур, а при $m(G)=6$, граф з двокутниками. Очевидно, що для гамільтонова контуру і для графа 3 двокутниками виконується умова

$$
\forall x, y \in X[|Z(x, y)|=|Z(y, x)|=1] .
$$

Таким чином, показана можливість виділення $з$ множини базових суграфів суграфа 3 мінімальною кількістю дуг (гамільтонів контур) і базового контуру 3 максимальною кількістю ребер (граф 3 двокутниками), що задовольняють властивості існування і єдиності і обчислення їх інваріанту $\mathrm{m}$.

Опишемо можливу методику побудови всього класу суграфів, для яких справедлива властивість (20). Позначимо через $G^{n}=$ $(\mathrm{X}, \mathrm{U}),|X|=n \quad$ граф, що задовольняє властивості $\forall x, y \in X[|Z(x, y)|=|Z(y, x)|=$ 1]. Тоді $G^{n}$ або ізоморфний $n$-кутник, або 
може бути отриманий з кінцевого числа $n_{i}$ кутників $G^{n_{i}}=\left(X_{i}, Y_{i}\right) X_{i} \subset X, U_{i} \subset U$. Другий варіант реалізується за рахунок додавання цих п-кутників, а потім покрокового склеювання вершин отриманого графа так, що склеєні на даному етапі вершини належать різним компонентам бізв'язності отриманого на попередньому кроці графа.

Якщо провести поділ циклів, тобто операцію, зворотну операції склеювання, то отримаємо деяку кількість бікомпонент, кожна з яких відповідає простому орциклу вихідного графа $G^{n}$ і $\epsilon$ гамільтоновим контуром.

Умова розкладання графа $G^{n}$ за деякою системою $G^{n_{i}}$. Такою умовою $€$ співвідношення потужностей носіїв $G^{n}$ і систем $G^{n_{i}}$ :

$n=\sum_{i=1}^{k}\left(n_{i}-1\right)+1 \quad 1 \leq k \leq n-1, \quad 2 \leq n_{i} \leq n$.

Таким чином, для вирішення задачі синтезу насамперед необхідно знайти цілі рішення рівняння

$$
n=\sum_{i=1}^{k}\left(n_{i}-1\right)+1 \quad \mathrm{k}=\overline{1, n-1}
$$

при системі обмежень $2 \leq n_{i} \leq n ; i=\overline{1, K}$. У загальному випадку для кожного $K$ вирішенню рівняння буде відповідати певна структура $G^{n_{i}}, i=1, K$. В межах класів суграфів, що мають однакову структуру, можуть існувати ізоморфні суграфи. Однак ніякі два суграфи з різних класів не ізоморфні.

У випадку $n=4$, рішенню підлягають три рівняння $n_{1}=4, \quad n_{1}+n_{2}=5, n_{1}+n_{2}+$ $n_{3}=6$ з відповідними системами обмежень

$$
2 \leq n_{1} \leq 4, \quad\left\{\begin{array} { l } 
{ 2 \leq n _ { 1 } \leq 4 } \\
{ 2 \leq n _ { 2 } \leq 4 ^ { \prime } }
\end{array} \quad \left\{\begin{array}{l}
2 \leq n_{1} \leq 4 \\
2 \leq n_{2} \leq 4 \\
2 \leq n_{3} \leq 4
\end{array}\right.\right.
$$

В результаті розв'язку цих рівнянь отримаємо з точністю до ізоморфізму всі шукані базові суграфи, число яких для $n=4$ дорівнює чотирьом (мал. 3).

Заключний етап пошуку раціональної структури бойового порядку полягає у мінімізації функціоналу $F(G)=\alpha W(G)+$ $\beta L(G)$. Безумовно, мова не може йти про сувору процедуру оптимізації, так як досить проблематичним $\epsilon$ питання завдання

$\begin{array}{llll}\text { коефіцієнтів } \alpha, & \beta . \text { Поки } & \text { визначимося } & 3 \\ \text { процедурами } & \text { оцінки } & \text { складності } & \text { i } \\ \text { максимальної } & \text { довжини } & \text { iнформаційного }\end{array}$

циклу графів.

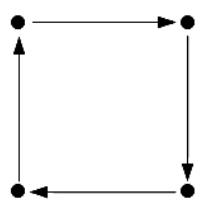

a

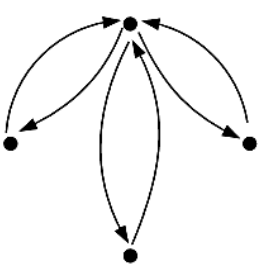

B
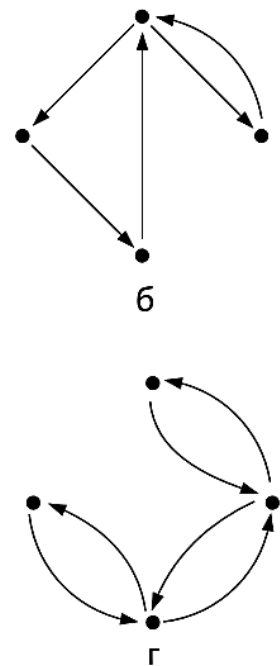

Малюнок 3 - Базові суграфи з точністю до ізоморфізму для $n=4$

Для оцінки складних графів доцільно орієнтуватися на методику, описану в [2]. Вона включає:

1. Оцінку складності множин за допомогою знаходження функції $C=f\left(n, t, d_{n}\right)$, де $n-$ число елементів множини; $t$ - число типів елементів; $d_{n}$ - характер розподілу елементів по типам. Умови, яким повинна задовольняти $C$, такі:

область ії значень повинна збігатися 3 множиною невід'ємних чисел;

C повинна бути монотонно зростаючою від кількості елементів і їх типів;

C повинна містити інформаційну міру різноманітності множини.

Абстрагуючись від кількісного складу деякої множини елементів представляється логічним вимір складності такої множини числом його елементів $C(A)=|A|=\operatorname{card} A$. Різноманітність елементів зручно оцінювати, спираючись на поняття ентропії з статистичної теорії інформації [3] і вважаючи, що ймовірність появи $i$-го елемента $P_{i}=\frac{n_{\mu}}{n}$, де $n_{\mu}$ - кількість елементів $\mu$-типу, до якого належить $i$-й елемент. Виходячи з цього,

$$
C(A)=n\left(1-\sum_{\mu=1}^{t} \frac{n_{\mu}}{n} \log _{2} \frac{n_{\mu}}{n}\right) .
$$


2. Оцінку складності графу за допомогою знаходження функції,

$$
\mathrm{C}=f\left(n, t, m, \tau, p, \delta_{n}, \delta_{m}, \delta_{p}, \delta\right),
$$

що відображає множину графів в множину невід'ємних чисел.

Беручи до уваги властивість адитивності інформації, пропонуємо наступний вигляд функції складності графу:

$$
C=n \log _{2}\left(2+\alpha_{m}\right)\left(H_{n}^{t}+H_{m}^{\tau}+H_{n}^{p}+1\right),
$$

де $\alpha=\frac{m}{m_{\max } \frac{m}{n(n-1)}}$, причому вважається, що одне неорієнтоване ребро еквівалентне двом орієнтованим:

$$
H_{n}^{t}=-\sum_{\mu=1}^{t} \frac{n_{\mu}}{n} \log _{2} \frac{n_{\mu}}{n}-\text { ентропійна міра }
$$
різноманітності вершин;

$H_{m}^{\tau}=-\sum_{q=1}^{\tau} \frac{m_{q}}{m} \log _{2} \frac{m_{q}}{m}-$ ентропійна міра різноманітності ребер;
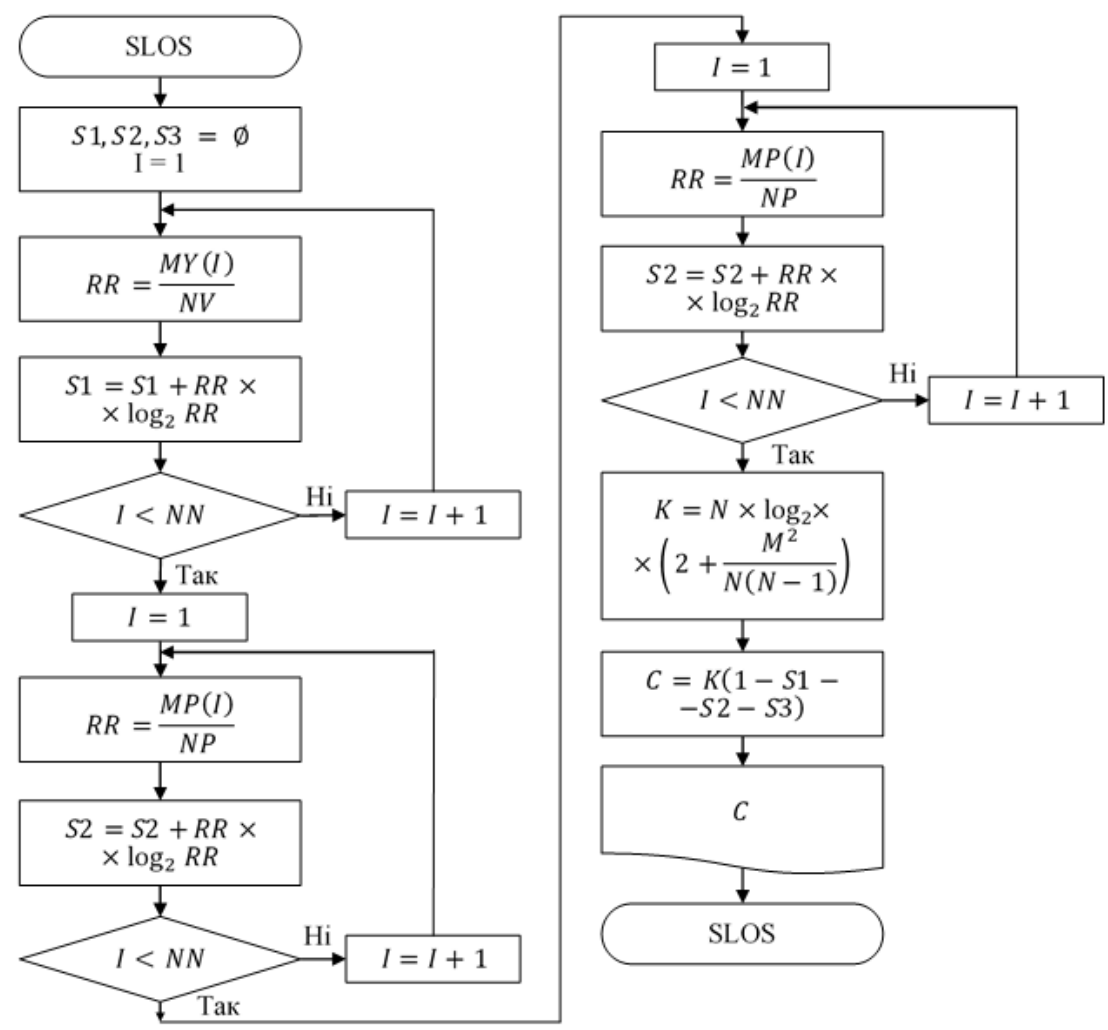

Малюнок 4 - Алгоритм оцінювання складності графу 


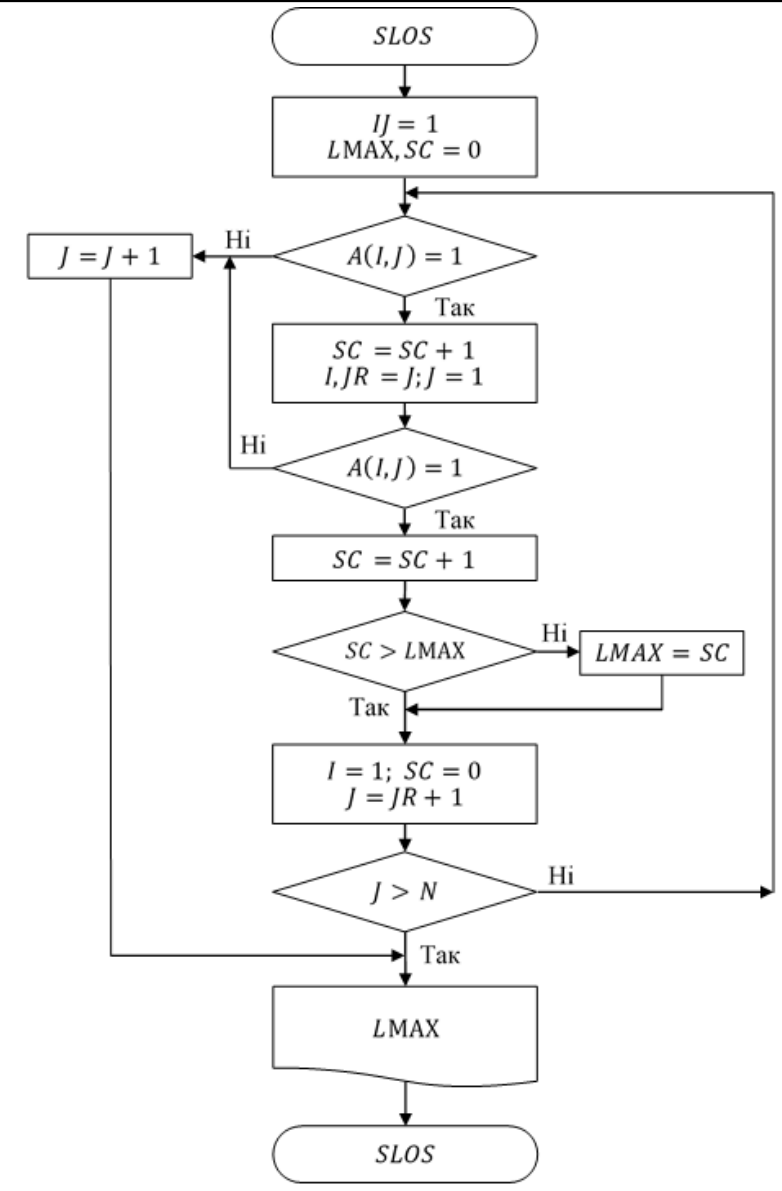

Малюнок 5 - Алгоритм пошуку максимальної довжини інформаційного циклу

Досліджувана оптимізаційна задача відноситься до класу задач дискретного програмування та може бути вирішена одночасно як графічно, так і аналітично [4-6]. Аналітичне рішення передбачає необхідність функціонального завдання залежності $W(L)$, що $є$ досить складною самостійною задачею. Альтернативний підхід полягає у заданні залежності $W(L)$ табличним способом та графічним рішенням оптимізаційної задачі у площині $W, L$. У цій площині функціонал буде визначений у дискретному ряді точок, що описується відношенням $W(L)$. Задавшись цільовою функцією $\alpha W+\beta L=$ const $\quad$ та переміщуючи їі у напрямі зростання $W$ та $L$, відшукаємо мінімум у місці першого перетинання прямої з множинами точок, що характеризують досліджувані графи. Кут нахилу прямої до осі $0 L$ визначається ваговими коефіцієнтами $\alpha, \beta$ та дорівнює $\varphi=$ $\operatorname{arctg}\left(-\frac{\alpha}{\beta}\right)$ (мал. 6).

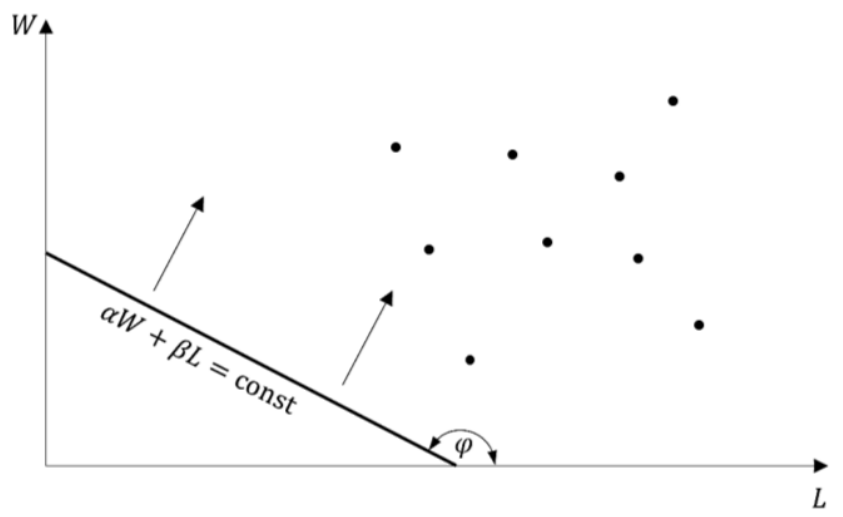

Малюнок 6 - Пошук мінімуму складності графа або довжини інформаційного циклу

Особливості тактичних та технічних аспектів організації управління бойовими порядками спільних авіаційних груп [7-9] можуть привести до двох часткових постановок досліджуваної задачі: для заданої максимальної довжини інформаційного циклу винайти граф мінімальної складності; при заданій складності знайти граф 3 мінімальною довжиною інформаційного циклу.

На відмінність від загального випадку, для розв'язання цих задач відповідно вводяться додаткові обмеження $L=L_{\text {зад }}$ або $W=W_{\text {зад }}$. Графічний сенс уведення цих обмежень полягає у тому, що з дискретної області у площині параметрів $(W, L)$ виокремлюється ряд

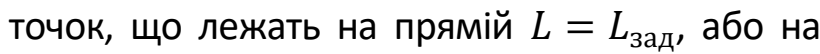

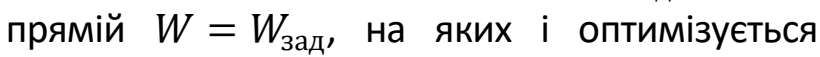
функціонал. Вочевидь, що для розглянутого виду функціоналу $\forall \alpha, \beta$ його мінімум буде знаходитись для першої часткової постановки задачі у найближчій від осі $O L$ точці, що лежить

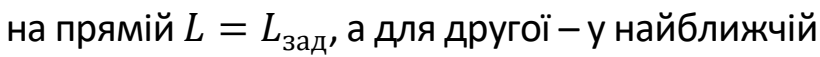
від осі $0 W$ точці, що лежить на осі $W=W_{\text {зад }}$.

Задачу пошуку базових суграфів повного графу Бержа 3 заданою довжиною максимального простого циклу пропонуємо розв'язувати у відповідності з алгоритмом (мал. 7). 


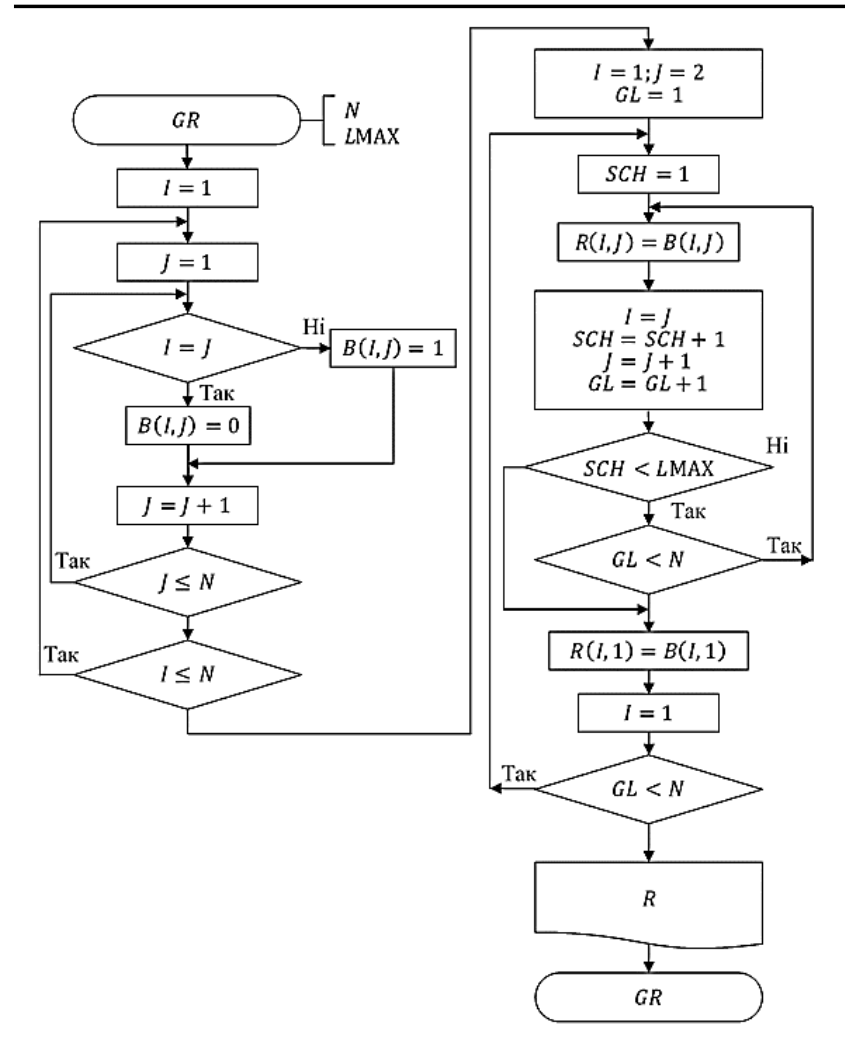

Мал. 7 - Алгоритм пошуку базових суграфів повного графу Бержа з заданою довжиною максимального простого циклу

Всі прості цикли винайденого суграфу мають єдину спільну вершину. Позначення: $N$ - число вершин графу, LMAX - довжина найбільшого простого циклу, $B$ - матриця суміжності повного графу Бержа, $R(N, N)-$ матриця суміжності одержаного базового суграфу, SCH - покажчик довжини циклу, GL покажчик охоплених циклами вершин.

\section{Висновки}

Реалізація описаних оптимізаційних процедур сприятиме синтезу стратегій управління спільними авіаційними групами та суттєво звузить область пошуку раціональних структур спільних бойових порядків пілотованої та безпілотної авіації. Подальші дослідження полягатимуть у конкретизації динамічних характеристик всіх елементів бойового порядку спільної авіаційної групи, при виконанні завдань за призначенням згідно Курсів бойової підготовки родів авіації, за всіма етапами польоту, що описуватимуться 3 використанням методу опорних точок [10], а прикінцеві висновки спиратимуться на результати моделювання.

\section{Список використаних джерел}

1. Ланге О. Целое и развитие в свете кибернетики // Исследование по общей теории системы. М.: Прогресс, 1969. - С.181251.

2. Хмеловский Г. А. Сложность системы и ее изменения // Автоматика. - 1982. - № 4. С. 67-69.

3. Колмогоров А.Н. Теория информации и теория графов. М.: Наука, 1981. - 304 с.

4. Трухаев Р. И. Энфлюэнтный анализ и принятие решений. М.: Наука, 1984. - 257 с.

5. Таха X. Введение в исследование операций. М.: Мир, 1985. Т.1. -479 с.

6. Сергиенко И.В. Математические модели и методы решения задач дискретной оптимизации. К.: Наукова думка, 1985. $384 \mathrm{c}$.

7. Артюшин Л. М. Задачі управління конфигурацією механічної системи // Прикладна механіка. К.: АН УРСР, 1987. - 23, № 2. - С. 89-95.

8. Артюшин Л. М. Оптимальне управління формуванням конфігурації механічної системи. Доповідь. АН УРСР. Кібернетика та обчислювальна техніка. Серія А. Физика.математика. та технічні. науки. К.: АН УРСР, 1987. - № 11. - С. 65-68.

9. Артюшин Л. М., Герасименко В.В., Коваль В.В. Метод формування спільної авіаційної групи // Сучасні інформаційні технології у сфері безпеки та оборони. - № 1 (40)/2021. C. 63-68. DOI: 10.33099/2311-7249/2021-401-63-68.

10. Крюков Н. П., Кремень М. А. Метод опорных точек // Авиация и космонавтика. - 1983. № 7. - С. 27-29. 


\title{
Синтез рациональных структур боевых порядков совместных авиационных групп
}

\author{
Леонид Артюшин ${ }^{1 \text { А }}$; Владимир Герасименко * 2 в ; Владимир Коваль 3 с \\ ${ }^{1}$ доктор технических наук, профессор, ведущий научный сотрудник, e-mail: artleonid2017@gmail.com, ORCID: 0000-0002-7488-7244 \\ 2 * Corresponding author: кандидат военных наук, докторант, e-mail: gerasimenko_v_v@nuou.org.ua, ORCID: 0000-0003-2014-7408 \\ 3 кандидат военных наук, с.н.с., начальник военно-научного управления, e-mail: gera410@ukr.net, ORCID: 0000-0002-6209-6779 \\ А Государственный научно-исследовательский институт авиации Украины, ул. Григория Андрющенко, 6В, г. Киев, 01135, Украина

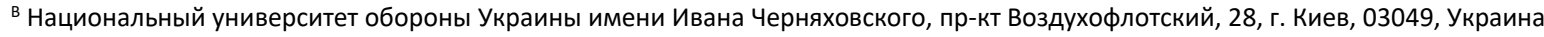 \\ с Генеральный штаб Вооруженных Сил Украины, пр-кт Воздухофлотский, 28, г. Киев, 03049, Украина
}

\begin{abstract}
Аннотация
Существующая стратегия управления боевым порядком, основанная на методе управления по ведущему или главному, естественно, не может стимулировать привлечение аппарата структурного анализа для решения управленческих задач. Мастерство фигур высшего пилотажа в составе группе сводится к уровню подготовки летчиков, возможности которых контролировать свое место в боевом порядке ограничены и заключены в схеме: ведущий - ведомый. Ориентация на автоматизацию управления совместными боевыми порядками пилотируемой и беспилотной авиации, при отсутствии пилота на борту беспилотного летательного аппарата, выводит проблему за рамки моделирования (имитации) действий летчика при исполнении группового полета и предусматривает постановку задач по структурной и параметрической оптимизации строя пилотируемых и беспилотных летательных аппаратов в пределах боевого порядка. Суть проблемы заключается в значительном повышении эффективности существующих принципов управления и реализации принципиально новых способов управления боевыми порядками, которые основаны, в том числе, на повышении возможностей средств межсамолетной навигации и контроля места самолета в боевом порядке. Одним из путей достижения этих целей является разработка методов поиска устойчивых и хорошо управляемых структур.
\end{abstract}

Ключевые слова: боевой порядок, совместная авиационная группа, автоматизация управления, сложный граф, матрица структуры, рациональная структура.

\section{Synthesis of rational structures of joint aviation groups combat formation}

\author{
Leonid Artyushin ${ }^{1 \mathrm{~A}}$; Volodymyr Herasymenko ${ }^{2 \mathrm{~B}}$; Volodymyr Koval $3 \mathrm{C}$ \\ ${ }_{1}^{1}$ Doctor of technical sciences, Professor, e-mail: artleonid2017@gmail.com, ORCID: 0000-0002-7488-7244 \\ ${ }^{2}$ Corresponding author: Candidate of military sciences, e-mail: gerasimenko_v_v@nuou.org.ua, ORCID: 0000-0003-2014-7408 \\ ${ }^{3}$ Candidate of military sciences, Senior Research Fellow, e-mail: gera410@ukr.net, ORCID: 0000-0002-6209-6779 \\ A State Aviation Research Institute of Ukraine, Kyiv, Ukraine \\ ${ }^{B}$ National Defence University of Ukraine named after Ivan Cherniakhovskyi, Kyiv, Ukraine \\ ${ }^{\mathrm{c}}$ General Staff of the Armed Forces of Ukraine, Kyiv, Ukraine
}

\begin{abstract}
The existing combat command and control strategy, based on the command and control method of the leader or chief, naturally cannot stimulate the involvement of a structural analyze to solve command and control problems. The skill of the aerobatics in the group is reduced to the level of training of pilots, whose ability to control their place in combat formation is limited and enclosed in the scheme: the leader - the led. The orientation to automate the command and control of joint combat formations of manned and unmanned aviation, in the absence of a pilot on board the unmanned aerial vehicle, takes the problem beyond the modeling (simulation) of the actions of the pilot in the performance of group flight and provides for the task of structural
\end{abstract}


and parametric optimization of the combat formation parameters of manned and unmanned aerial vehicles in the combat formation area. The essence of the problem lies in significantly improving the effectiveness of existing principles of command and control and implementation of fundamentally new ways of command and control by combat formations, which are based on improving the capabilities of navigation and monitoring the aircraft's place in combat formation. One way to achieve these goals is to develop methods to find sustainable and well-controlled structures.

Keywords: combat formation, joint aviation group, automatization of command and control, complex graph, matrix of structure, rational structure.

\section{References}

1. Lange O. (1969) Celoe i razvitie v svete kibernetiki // Issledovanie po obshhej teorii sistemy. [Whole and development in light of cybernetics / Study on general system theory]. Moscow: Progress. S. 181-251.

2. Hmelovskij G.A. (1982) Slozhnost' sistemy i ee izmenenija // Avtomatika. [Complexity of the system and its changes / Automation]. № 4. S. 67-69.

3. Kolmogorov A.N. (1981) Teorija informacii $i$ teorija grafov. [Information theory and graph theory]. Moscow: Nauka. 304 s.

4. Truhaev R.I. (1984) Jenfljujentnyj analiz i prinjatie reshenij. [Enfluent analysis and decision-making]. Moscow: Nauka. $257 \mathrm{~s}$.

5. Taha H. (1985) Vvedenie $v$ issledovanie operacij. [Introduction to operations research]. Moscow: Mir. T.1. 479 s.

6. Sergienko I.V. (1985) Matematicheskie modeli i metody reshenija zadach diskretnoj optimizacii. [Mathematical models and methods for solving discrete optimization problems]. Kyiv: Naukova dumka. $384 \mathrm{~s}$.

7. Artyushyn L.M. (1987) Zadachi upravlinnia konfyhuratsiieiu mekhanichnoi systemy //
Prykl. mekhanika. [Tasks of mechanical system configuration management // Applied mechanics]. Kyiv: AN URSR. 23, № 2. S. 89-95.

8. Artyushyn L.M. (1987) Optymalne upravlinnia formuvanniam konfihuratsii mekhanichnoi systemy. Dopov. AN URSR. Kibernetyka ta obchysliuvalna tekhnika. Seriia A. Fyz.-mat. ta tekhn. nauky. [Optimal control of mechanical system configuration formation. Rep. USSR Ac. of Scienc. Cybernetics and computing. Series A. Phys.-math. and tech. Science]. Kyiv: AN URSR. № 11. S. 65-68.

9. Artyushyn L.M., Herasymenko V.V., Koval V.V. (2021) Metod formuvannia spilnoi aviatsiinoi hrupy // Suchasni informatsiini tekhnolohii u sferi bezpeky ta oborony. [Method of formation of joint aviation group // Modern information technologies in the sphere of security and defence]. № 1 (40). S. 63-68. DOI: 10.33099/2311-7249/2021-40-1-63-68.

10. Krjukov N.P., Kremen M.A. (1983) Metod opornyh tochek // Aviacija i kosmonavtika. [Method of reference points / Aviation and space]. № 7. S. 27-29. 